\title{
Distribuição Espacial da Meleira do Mamoeiro em Zonas de Trópico Úmido e Trópico Semi-Árido
}

\author{
Carlos A. Vidal ${ }^{1}$, Francisco F. Laranjeira ${ }^{2}$, Antônio S. Nascimento ${ }^{2}$ \& Tuffi C. Habibe ${ }^{3}$ \\ ${ }^{1}$ Agência Estadual de Defesa Agropecuária da Bahia (ADAB), Cruz das Almas, BA, Brasil, Praça Suerdick S/N, \\ CEP 4438-000; '²mbrapa Mandioca e Fruticultura, Cruz das Almas, BA, Brasil, Cx. Postal 007, CEP 44380-000, fax: (75) \\ 621 2149, e-mail: chico@ cnpmf.embrapa.br; ${ }^{3}$ Mestrando em Ciências Agrárias pela Universidade Federal da Bahia (UFBA)
}

(Aceito para publicação em 15/09/2003)

Autor para correspondência: Francisco F. Laranjeira

VIDAL, C.A., LARANJEIRA, F.F., NASCIMENTO, A.S. \& HABIBE, T.C. Distribuição espacial da meleira do mamoeiro em zonas de trópico úmido e trópico semi-árido. Fitopatologia Brasileira 29:276-281. 2004.

\section{RESUMO}

O vírus da meleira, transmitido por Bemisia tabaci, é um dos maiores problemas da cultura do mamoeiro (Carica papaya), sendo responsável por perdas de até $100 \%$ na produção. Com o objetivo de compreender melhor sua epidemiologia e gerar subsídios para estudos da influência de fatores culturais e bioecológicos na dinâmica da doença, avaliou-se a distribuição espacial de plantas afetadas pela meleira em zonas de Trópico Úmido e Trópico Semi-árido, em 15 plantios comerciais em Eunápolis-BA e Petrolina-PE, entre jan. 2000 e mar. 2001. As áreas foram mapeadas anotando-se a posição de cada planta e a presença ou ausência de sintomas. Foram consideradas doentes aquelas que apresentavam frutos com exsudação espontânea do látex, látex muito fluido, frutos borrados e/ou folhas do ápice com o bordo necrosado. Pelas análises de sequiências ordinárias, índice de dispersão, áreas isópatas e ajuste dos logaritmos das variâncias binomial e de acordo com a lei de Taylor, observaram-se maior agregação nas linhas de plantio que entre linhas e uma agregação de mediana a forte em sub-áreas $(1,4<\mathrm{ID}<3,1)$. Na maioria dos lotes, as áreas de maior incidência concentraram-se nas bordas dos talhões, o que indica que a migração de vetores assume um papel importante na disseminação da doença. Em alguns casos foi possível detectar a presença de focos isolados no interior dos lotes, o que sugere a formação de colônias dos vetores e transmissão planta a planta a partir de inóculo secundário. Não foram observadas diferenças significativas na distribuição espacial de plantas doentes entre as áreas das duas regiões.

Palavras-chave adicionais: Carica papaya, mamão, moscabranca, epidemiologia.

\section{ABSTRACT}

Spatial patterns of papaya sticky disease in brazilian semi arid and rain forest regions

Papaya Sticky Disease (PSD) is caused by a whitefly-borne virus and is one of the most important problems of the papaya (Carica papaya) industry in Brazil, causing yield losses of up to $100 \%$. In order to better understand its epidemiology and generate data for studies on influence of cultural practices and bioecological features on disease dynamics, 15 papaya orchards were evaluated in Eunápolis, Bahia (Rain Forest Region) and Petrolina, Pernambuco (Semi Arid Tropics) between January 2000 and March 2001. The areas were mapped taking into consideration the row or column position of each plant and its disease status. A given plant was considered diseased when it's fruits showed latex exudation, fluid latex and latex spots.
The maps were analised by ordinary runs, dispersion index, Taylor law fitting and isopath areas. Results showed greater aggregation within rows than across rows which can be the consequence of a vector limited movement, with a trend to colonizing nearest plants; The dispersion index indicated a medium to strong aggregation within sub areas and this result was confirmed by Taylor law fitting. In most of the areas, higher disease incidence was detected at orchard edges. This may indicate that vector migration can assume important role in PSD virus dissemination. In some cases it was possible to detect the presence of isolated foci inside orchards, an indication of vector colony formation and plant to plant transmission from secondary inoculum. Significant differences were not observed between rain forest and semi-arid regions.

\section{INTRODUÇÃO}

Apesar da expansão dos cultivos, do aumento da produção e da melhoria da qualidade do fruto nos últimos dez anos, a cultura do mamoeiro (Carica papaya L.) no Brasil continua sendo afetada por importantes doenças. Nesse quadro destacam-se a mancha anelar e a meleira. Juntas, elas vêm causando prejuízos anuais de R \$ 1,2 milhão, considerando-se apenas o Estado do Espírito Santo (Rodrigues et al., 1989a).

Constatada na década de 80 afetando pomares no Sul da Bahia e no Norte do Espírito Santo, a meleira foi descrita como uma anormalidade cuja característica principal era a exsudação espontânea do látex de frutos, que posteriormente oxidava, dando um aspecto borrado ou 'melado' ao fruto, do qual deriva seu nome (Nakagawa et al., 1987). Além do sintoma típico da meleira, plantas infetadas podem apresentar frutos com manchas claras e deformações nos frutos. Em alguns casos a polpa pode ser afetada, assumindo aspecto esponjoso e tendo seu sabor alterado. Podem aparecer sintomas necróticos nos bordos de folhas novas, decorrentes da exsudação do látex (Nakagawa et al., 1987; Rodrigues et al.,1989a,b; Kitajima et al., 1993). De acordo com Habibe et al. (2003), pode ocorrer 
Distribuição espacial da meleira do mamoeiro em zonas de ...

também exsudação e oxidação de látex nos bordos das pétalas das flores em fase de floração e/ou frutificação, seguida de necrose e exsudação e oxidação do látex nas nervuras das folhas do ápice e terço mediano das plantas.

A meleira é atualmente o maior problema fitossanitário da cultura do mamoeiro no sul e nordeste da Bahia e norte do Espírito Santo, sendo responsável por perdas de 30 a $100 \%$ na produção dos pomares afetados (Rodrigues et al.,1989a; Barbosa et al., 1998). Além disso, já foi relatada a relação entre a meleira e incidência de mosca das frutas, em que frutos afetados pela doença são muito mais suscetíveis ao inseto (Nascimento et al., 1999). Até o momento, a estratégia de controle mais eficiente tem sido a remoção de fontes de inóculo, com o roguing de plantas doentes (Ventura et al., 2001).

Em 2000, Zambolim et al. (2000) relataram a purificação de vírus à partir de plantas infetadas pela meleira. As partículas purificadas foram inoculadas em plantas sadias de mamoeiro que posteriormente desenvolveram sintomas da doença. $\mathrm{O}$ vírus da meleira possui partículas com aproximadamente $45 \mathrm{~nm}$ de diâmetro, sendo composto de uma única molécula de dsRNA e pertence a um novo gênero não relacionado a outros vírus que infetam plantas, vertebrados e invertebrados (Zambolim et al., 2000).

$\mathrm{O}$ vírus da meleira é transmitido mecanicamente, através de ferimentos produzidos por instrumentos perfurantes contaminados (Barbosa et al., 1998), mas todas as evidências apontam para a não-transmissão por sementes (Meissner Filho et al., 2003). Recentemente, foi comprovada a transmissão desse vírus pelo biotipo B de Bemisia tabaci Gennadius, mas não por pulgões ou cigarrinhas (Vidal, 2002).

Além da transmissibilidade, já foram investigados alguns outros aspectos da epidemiologia da doença. Tatagiba et al. (2002), em trabalho sobre a evolução temporal da meleira, detectaram um aumento na percentagem de plantas sintomáticas, especialmente com necrose nas folhas, conforme as temperaturas médias diminuíam na região do estudo. Quanto ao aspecto espacial, Rodrigues et al. (1989b), usando a técnica de seqüências ordinárias, mostraram que as epidemias começavam de maneira aleatória, mas tendiam à agregação dentro das linhas de plantio. Maffia et al. (1993), por sua vez, encontraram alta agregação de plantas afetadas pela meleira.

O estudo do progresso e disseminação de patógenos é essencial para a correta caracterização de um patossistema. A análise do arranjo espacial fornece subsídios para entender a etiologia, verificar a eficiência de sua dispersão e gerar informações sobre a influência de fatores culturais, biológicos e do ambiente na dinâmica populacional de patógenos/doenças. Mais que caracterizar, o estudo epidemiológico fornece dados para o delineamento de estratégias de controle das doenças. Dentro desse contexto, o estudo de aspectos epidemiológicos da meleira é crucial. Este trabalho foi realizado com o objetivo de compreender melhor a epidemiologia da meleira, ampliando os níveis de organização espacial estudados por Rodrigues et al. (1989b) e Maffia et al. (1993), além de caracterizar a distribuição espacial de plantas afetadas pela doença em zonas de Trópico Úmido e Trópico Semi-árido.

\section{MATERIAL E MÉTODOS}

\section{Áreas}

Avaliou-se a distribuição espacial de plantas afetadas pela meleira de janeiro de 2000 a março de 2001, nos municípios de Eunápolis-BA e Petrolina-PE. Para cada área de cultivo de mamoeiro analisada (Tabela 1), foram registrados a variedade plantada, idade do pomar, número de plantas, plantios circunvizinhos e direção do vento.

As avaliações foram feitas percorrendo-se toda a área plantada, anotando-se as plantas doentes, plantas sem sintomas e plantas erradicadas, adotando-se como planta doente aquela que apresentava frutos com exsudação espontânea do látex, látex muito fluido, frutos borrados e/ou folhas do ápice com o bordo necrosado.

\section{Distribuição espacial}

Foram utilizadas quatro técnicas para esclarecer aspectos da disseminação do patógeno. A primeira, Análise de Seqüências Ordinárias, determina a agregação de plantas doentes numa mesma linha de plantio. O Índice de Dispersão gera informação sobre a tendência de plantas doentes aparecerem próximas de outras plantas doentes em sub-áreas do talhão examinado, em cada avaliação. O Ajuste à Lei de Taylor indica tendência à agregação ao longo de toda a epidemia. A Análise de Áreas Isópatas (AAI) mostra o padrão geral das plantas sintomáticas, delineando os focos, a fonte primária de inóculo e a direção de disseminação da epidemia.

\section{Análise de sequiências ordinárias (ASO)}

O índice Zso foi calculado para cada talhão. Nesse estudo foram seguidas as definições e diretrizes de Gibbons (1976) e Madden et al. (1982). Para essa análise, a hipótese de nulidade considera que um dado conjunto ordenado de símbolos (plantas sintomáticas) está distribuído de forma aleatória. A hipótese alternativa considera que as plantas doentes estão agregadas (Madden et al., 1982). Os talhões foram considerados com agrupamento de plantas sintomáticas, ao nível de 5\% de significância, se o valor de Zso foi igual ou inferior a -1,64. Em contrapartida, valores de Zso superiores a 1,64 indicam arranjo regular das plantas doentes, também com probabilidade de erro de $5 \%$. A premissa básica para o uso de tal análise foi a de que agrupamento significativo de plantas afetadas indica que o patógeno está se disseminando predominantemente de uma planta a outra imediatamente vizinha.

Foram calculados valores do índice Zso para cada linha de plantio e também para cada alinhamento perpendicular às linhas de plantio. Calculou-se então o percentual de sequências com agregação de plantas doentes em cada área e direção.

\section{Índice de Dispersão e Ajuste à lei de Taylor modificada}

Cada mapa foi dividido em "quadrats" de tamanhos 
TABELA 1 - Áreas mapeadas quanto à incidência da meleira do mamoeiro (Carica papaya)

\begin{tabular}{llcl}
\hline \hline Local & $\begin{array}{l}\text { Variedade } \\
\text { de mamoeiro }\end{array}$ & $\begin{array}{c}\text { Número de } \\
\text { plantas }\end{array}$ & $\begin{array}{l}\text { Data da } \\
\text { avaliação }\end{array}$ \\
\hline Petrolina 01 & Solo & 1470 & janeiro 2000 \\
Petrolina 02 & Formosa & 1620 & janeiro 2000 \\
Petrolina 03 & Formosa & 1620 & agosto 2000 \\
Petrolina 04 & Formosa & 1620 & outubro 2000 \\
Petrolina 05 & Formosa & 1620 & novembro 2000 \\
Petrolina 06 & Formosa & 1620 & janeiro 2001 \\
Petrolina 07 & Formosa & 1620 & marco 2001 \\
Petrolina 08 & Solo & 1104 & janeiro 2001 \\
Petrolina 09 & Solo & 780 & agosto 2000 \\
Petrolina 10 & Solo & 248 & agosto 2000 \\
Petrolina 11 & Solo & 216 & agosto 2000 \\
Eunápolis 01 & Solo & 1376 & janeiro 2000 \\
Eunápolis 02 & Solo & 1833 & outubro 2000 \\
Eunápolis 03 & Solo & 420 & outubro 2000 \\
Eunápolis 04 & Solo & 280 & outubro 2000 \\
\hline
\end{tabular}

2x2, 3x3 e 4x4 plantas. Com o uso do Macro "Quadratizer" para Excel (T.R. Gottwald, USDA-ARS, Fort Pierce, FL, EUA), calcularam-se as variâncias binomial (Vbin) e observada (Vobs). As regressões $\left[\log (\right.$ Vbin $)=A+b^{*}$ $\log$ (Vobs)] foram feitas por meio do método dos quadrados mínimos (Hughes \& Madden, 1992) utilizando-se o programa Statistica 5.0. A significância das relações entre $\log \left(\mathrm{v}_{\mathrm{bin}}\right)$ e $\log \left(\mathrm{v}_{\mathrm{obs}}\right)$ foi determinada pelo teste $\mathrm{F}$ e a adequação do ajuste do modelo aos dados foi determinada por meio dos valores dos coeficientes de determinação $\left(\mathrm{R}^{2}\right)$ e dos padrões de distribuição dos resíduos, em gráficos de resíduos versus valores previstos de $\log \left(\mathrm{v}_{\mathrm{bin}}\right)$ (Madden et al., 1995).

A igualdade do parâmetro $b$ a 1 foi testada através do teste $\mathrm{t}$ (Madden et al., 1995), usando a estimativa do parâmetro e seu erro padrão. A hipótese alternativa foi a de $b>1$. Valores de $b$ significativamente diferentes de 1 ao nível de $1 \%$ de probabilidade foram considerados indicativos de agregação e valores estatisticamente iguais a 1 foram considerados indicativos de aleatoriedade.

O índice de dispersão foi calculado para todas as avaliações e os três tamanhos de "quadrat" por meio da relação $\mathrm{ID}=\mathrm{v}_{\text {obs }} / \mathrm{v}_{\text {bin }}$ (Gottwald et al., 1996). O afastamento da aleatoriedade foi determinado através de teste de $\chi^{2}$ ao nível de $1 \%$ de significância. A hipótese nula foi a de que o padrão observado era aleatório e a hipótese alternativa a de que era agregado. Valores de ID que não diferiram estatisticamente de um foram considerados como indicativo de aleatoriedade dos dados. De forma complementar, valores estatisticamente superiores a um foram tomados como indicativos de agregação.

\section{Áreas isopatas}

O estabelecimento das áreas isópatas para cada local e avaliação foi feito no utilitário Statistica 5.0, por meio do procedimento de uniformização dos quadrados mínimos, ponderados pela distância. Nessa determinação, foi utilizada a matriz dos valores ( 0 , planta sadia; 1 , planta doente) originais dos mapas. Os níveis de cada área isópata, para cada avaliação, foram padronizados, com o objetivo de realçar possíveis diferenças (Laranjeira, 1997).

\section{RESULTADOS E DISCUSSÂO}

\section{Análise de seqüências ordinárias}

A percentagem de seqüências agregadas ( $p s a)$ variou muito, tanto dentro das linhas de plantio (0\% a 73\%) quanto entre linhas de plantio (0 a 39\%) (Tabela 2). Essa variação ocorreu nas duas zonas climáticas consideradas, não havendo evidências de diferenças entre elas. De fato, a média de psa das duas regiões - Trópico Úmido e Trópico Semi-Árido não diferiu estatisticamente pelo teste $t$, nem na direção das linhas $(\mathrm{P} \leq 0,97)$ nem na sua perpendicular $(\mathrm{P} \leq 0,60)$. Como a evolução da doença em cada lote não foi acompanhada, a variação na psa pode refletir o estado da epidemia em dados momentos, já que é natural que o psa sofra variações com o progresso de uma doença. De maneira geral o psa da direção "Dentro das linhas" foi maior que entre linhas (Teste $t, \mathrm{P} \leq 0,01$ ). Isso pode indicar que o vetor do vírus da meleira tende a se movimentar mais dentro das linhas de plantio que em outras direções. O que motivaria esse comportamento, porém, poderia ser explicado por duas hipóteses: i) o vetor simplesmente procura plantas mais próximas; ii) sua movimentação sofre influência da movimentação humana per se ou de máquinas, no sentido das linhas de plantio, quando da execução de tratos culturais e da colheita. Por outro lado, uma maior agregação dentro das linhas de plantio pode também ser reflexo de transmissões mecânicas pelo uso de ferramentas contaminadas.

Agregação de plantas afetadas pela meleira na linha de plantio já havia sido detectada por Rodrigues et al. (1989b). No entanto os autores apenas comentam que observaram aumento na agregação ao longo de uma epidemia, mas não

TABELA 2 - Percentagem de sequiências agregadas em duas direções e 15 lotes de observação, pela análise de seqüências ordinárias em pomares de mamoeiro (Carica papaya) com meleira

\begin{tabular}{lcc}
\hline \hline \multirow{2}{*}{ Lote } & \multicolumn{2}{c}{ Percentagem de Seqüências Agregadas } \\
\cline { 2 - 3 } \cline { 2 - 3 } Dentro das linhas & Entre linhas \\
\hline Petrolina 01 & 12 & 10 \\
Petrolina 02 & 40 & 39 \\
Petrolina 03 & 31 & 16 \\
Petrolina 04 & 73 & 17 \\
Petrolina 05 & 50 & 11 \\
Petrolina 06 & 33 & 34 \\
Petrolina 07 & 36 & 22 \\
Petrolina 08 & 29 & 8 \\
Petrolina 09 & 0 & 0 \\
Petrolina 10 & 20 & 8 \\
Petrolina 11 & 0 & 0 \\
Eunápolis 01 & 52 & 24 \\
Eunápolis 02 & 20 & 0 \\
Eunápolis 03 & 22 & 0 \\
Eunápolis 04 & 9 & 28 \\
\hline
\end{tabular}


Distribuição espacial da meleira do mamoeiro em zonas de ...

oferecem dados numéricos que possam ser comparados com os apresentados neste estudo.

\section{Índice de dispersão (ID)}

No "quadrat" 2 x2 plantas (Tabela 3 ) obteve-se o maior número de lotes com agregação significativa (12), embora o $4 \times 4$ plantas tenha tido maior média de ID que $2 \times 2$ e $3 \times 3$, que não diferiram entre si (Tukey, $\mathrm{P} \leq 0,01$ ). A maioria dos lotes com agregação no "quadrat" $2 \times 2$ plantas manteve a tendência nos tamanhos 3x3 e 4x4 plantas. Apenas três áreas, duas em Petrolina e uma em Eunápolis, não tiveram ID indicativo de agregação em qualquer dos "quadrats". Considerando todos os IDs calculados, $59 \%$ apresentaram valores acima de dois, o que se pode considerar como indicativo de alta agregação. Tal conclusão é similar à obtida por Maffia et al. (1993), mas eles não apresentam dados numéricos que possam ser comparados aos obtidos neste estudo.

No caso das sub-áreas analisadas ("quadrats"), a agregação observada pode estar relacionada com aspectos bioecológicos do vetor do patógeno. Não foi observada diferença significativa entre os ID das duas regiões (Teste $t$, $\mathrm{P} \leq 0,497$ ), o que indica, a princípio, que os processos de disseminação das epidemias de meleira não se alteram em função de padrões gerais das variáveis climáticas.

\section{Aplicação da lei de Taylor modificada (LTM)}

Após a regressão do logaritmo da variância observada pelo logaritmo da variância binomial estimada, foi possível determinar os valores dos parâmetros $b$ e $A$ (Figura 1). Como o conjunto de informações da região de Eunápolis é relativamente pequeno, não foi possível aplicar a regressão para as duas regiões, optando-se pelo agrupamento dos dados.

Os valores dos parâmetros $\mathrm{A}$ e $\mathrm{b}$ foram superiores a 0 e 1, respectivamente, para os três tamanhos de "quadrat" (Teste

TABELA 3 - Índices de dispersão (Vobs/Vbin) da meleira do mamoeiro (Carica papaya) para três tamanhos de "quadrat" em áreas em Petrolina, PE e Eunápolis, BA

\begin{tabular}{lccc}
\hline \hline \multirow{2}{*}{ Lote } & \multicolumn{3}{c}{ quadrats } \\
\cline { 2 - 4 } & 2 x 2 plantas & 3 x 3 plantas & $\mathbf{4}$ x 4 plantas \\
\hline Petrolina 01 & $1,62^{*}$ & $2,31^{*}$ & $3,08^{*}$ \\
Petrolina 02 & $2,02^{*}$ & $2,18^{*}$ & $2,63^{*}$ \\
Petrolina 03 & 1,04 & 1,11 & 1,26 \\
Petrolina 04 & $2,02^{*}$ & $2,46^{*}$ & $3,07^{*}$ \\
Petrolina 05 & $1,64^{*}$ & $1,65^{*}$ & $1,95^{*}$ \\
Petrolina 06 & $1,94^{*}$ & $2,36^{*}$ & $3,02^{*}$ \\
Petrolina 07 & $1,65^{*}$ & $2,03^{*}$ & $2,58^{*}$ \\
Petrolina 08 & $2,03^{*}$ & $2,27^{*}$ & $3,45^{*}$ \\
Petrolina 09 & $1,65^{*}$ & $1,67^{*}$ & $2,13^{*}$ \\
Petrolina 10 & $1,82^{*}$ & $2,22^{*}$ & $1,96^{*}$ \\
Petrolina 11 & 1,16 & 1,15 & 1,07 \\
Eunápolis 01 & 0,98 & 0,96 & 1,17 \\
Eunápolis 02 & $1,94^{*}$ & $1,91^{*}$ & $2,88^{*}$ \\
Eunápolis 03 & $1,38^{*}$ & 1,51 & $2,44^{*}$ \\
Eunápolis 04 & $1,86^{*}$ & $2,23^{*}$ & 1,73 \\
\hline
\end{tabular}

(*) indica valores estatisticamente superiores a $1(\mathrm{P}<0,01)$ t, $\mathrm{P}<0,01$ ), indicando agregação. Esse resultado confirma o obtido para o índice de dispersão. O parâmetro b foi estatisticamente similar para os três "quadrats" (Tukey, $\mathrm{P}<0,01)$ e seus valores $[1,14<\mathrm{b}<1,20]$ podem ser considerados indicativos de agregação fraca. $\mathrm{O}$ contraste entre os resultados da lei de Taylor e do índice de dispersão, ou seja, um indicando agregação de média a forte e outro indicando agregação fraca, refletem as características das técnicas. O índice de dispersão apresenta resultados pontuais, ou seja, em situações específicas a agregação é maior, enquanto que a lei de Taylor, grosso modo, indica o padrão geral nas diversas áreas. Nesse caso, foram agrupadas áreas com IDs altos e lotes com IDs indicativos de aleatoriedade o que se refletiu nos resultados.

\section{Determinação de áreas isópatas (AI)}

$\mathrm{Na}$ maioria dos lotes as áreas de maior incidência concentravam-se nas bordas dos talhões (Figura 2 b,c,d,e,f). Padrões similares a esse já foram encontrados para geminivírus transmitidos por mosca-branca em mandioca (Manihot esculenta Crantz), quiabeiro [Abelmoschus esculentus (L.) Moench] e fumo (Nicotiana tabacum L.) na África e na Índia (Fargette et al., 1993). Esses resultados indicam que a migração de vetores assume um papel importante na disseminação da doença, como já demonstrado por Polston et al. (1996) para o Tomato mottle virus (TMoV), família Geminiviridae, gênero Begomovirus; em cultivos de tomateiro (Lycopersicon esculentum Mill.) submetidos a intensa aplicação de inseticidas.

Por outro lado, em alguns casos foi possível detectar a presença de focos isolados no interior dos lotes (Figura 2 b,d), o que sugere a formação de colônias dos vetores e transmissão planta a planta a partir de inóculo secundário. De fato, a colonização do mamoeiro pela mosca branca já foi relatada na Índia, onde B. tabaci provavelmente transmite Papaya leaf curl virus (PaLCV), família Geminiviridae, gênero Begomovirus (Sangeeta, 1998). No Hawai, B. tabaci biótipo B, foi encontrada colonizando plantas de mamoeiro, alcançando altos níveis populacionais (Costa, 1993), e no Mato Grosso do Sul, Vieira \& Corrêa (2001) constataram a presença de mosca-branca em plantios de mamoeiro cv. Baixinho de Santa Amália mantidos em telado. Verificaram-se grandes quantidades de ninfas e adultos nas folhas maduras e nos ponteiros das plantas.

Os resultados obtidos - agregação de plantas doentes, maior incidência associada às bordas e provável existência de ciclos secundários - permitem inferir que a estratégia de remoção de fontes de inóculo (Ventura et al., 2001) será tanto mais eficiente quanto mais precoce e acurada for a detecção das plantas afetadas. Além disso, estudos de bioecologia de B. tabaci em soja [Glycine $\max$ (L.) Merril] indicam que o principal fator na flutuação populacional do inseto é a variação espaço-temporal na quantidade de plantas hospedeiras (Hirano et al., 1993). Por inferência, conclui-se que quanto menor a densidade de plantas numa dada área, menor a probabilidade de aumento populacional do inseto e, portanto, menor a 


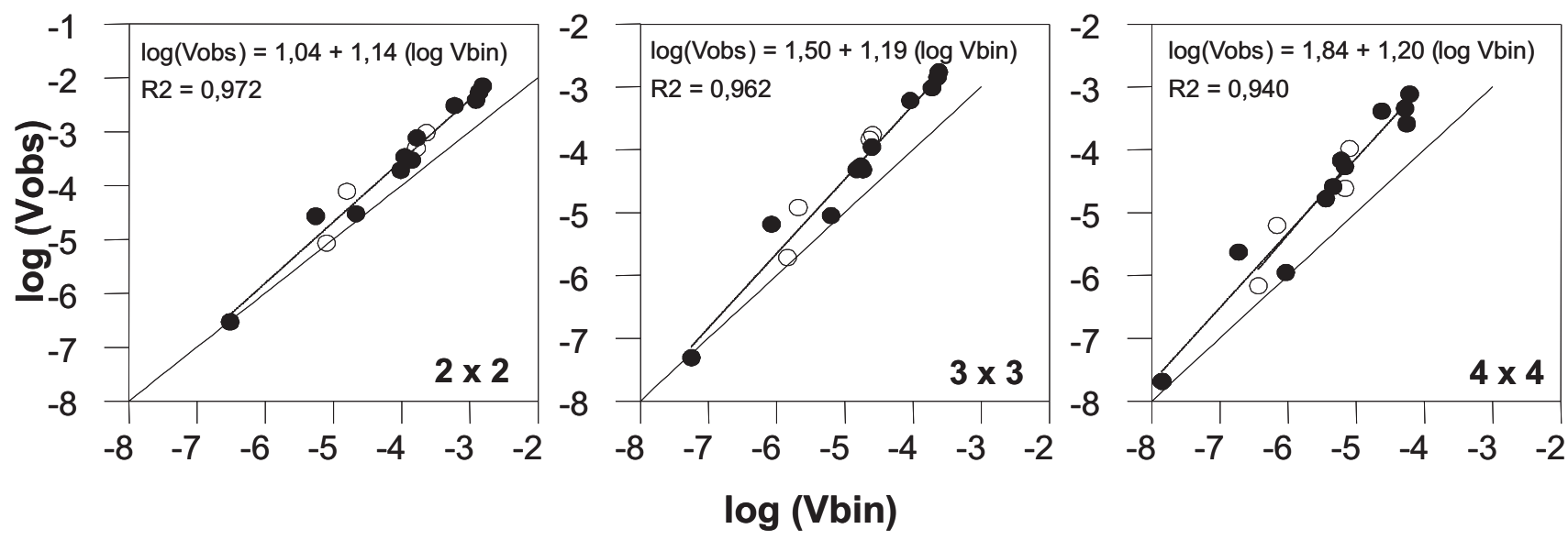

FIG. 1 - Relação entre o logaritmo da variância binomial (log Vbin) e o logaritmo da variância observada (log Vobs) da incidência da meleira do mamoeiro (Carica papaya) para três tamanhos de "quadrat", em áreas com incidência da meleira. Dados agrupados das quinze áreas; círculos cheios, áreas de Petrolina e círculos vazios, áreas de Eunápolis.
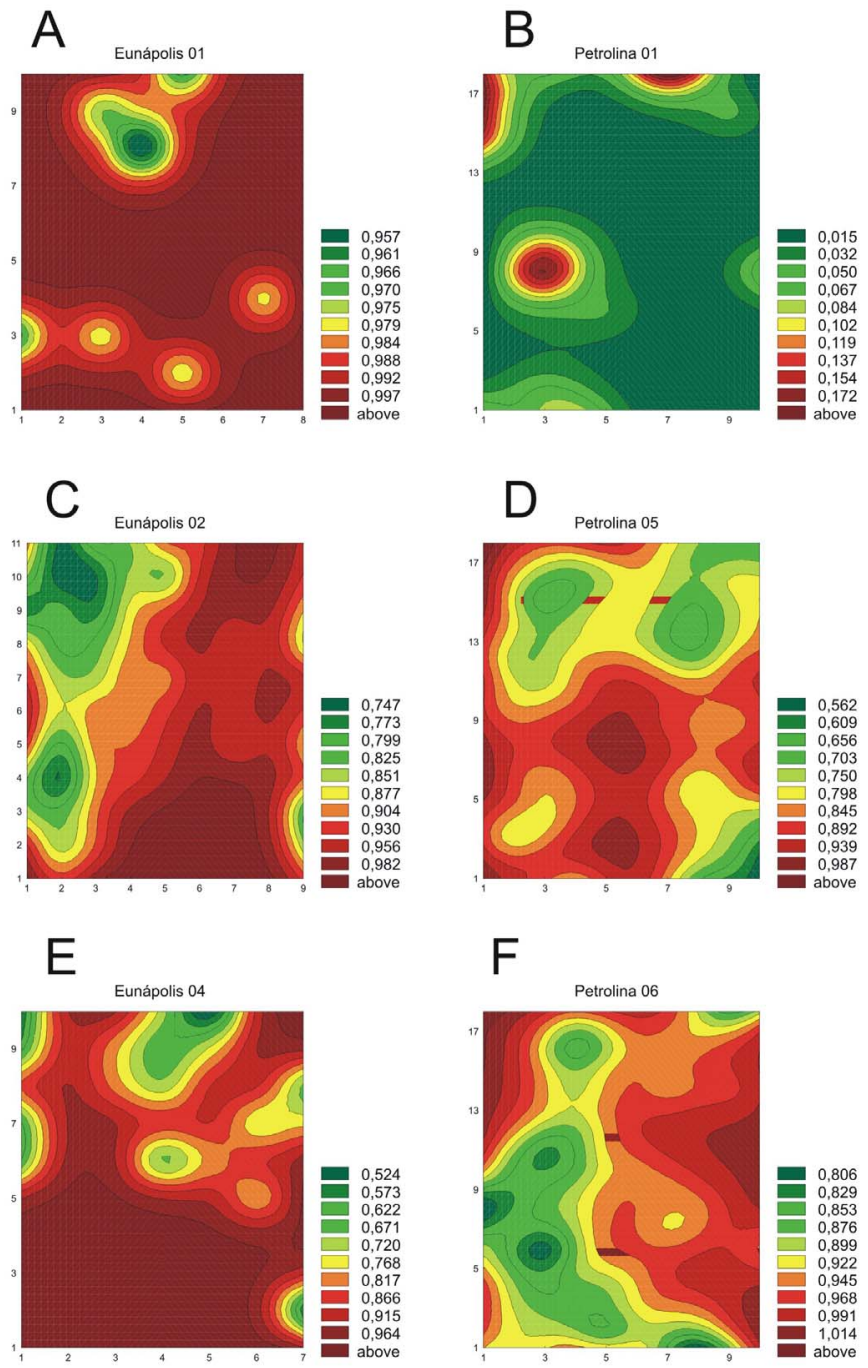

FIG. 2 - Áreas isópatas da meleira do mamoeiro (Carica papaya) em três áreas em Petrolina, PE e três em Eunápolis, BA. probabilidade de transmissão de eventuais patógenos. Isso explicaria a eficiência do roguing.

Este trabalho evidenciou que, a princípio, não há razões para se suspeitar de processos epidêmicos distintos para a meleira do mamoeiro em função da zona climática onde o cultivo está localizado. Considerando o vetor como o elemento-chave desse patossistema, essa conclusão encontra amparo no estudo de Hirano et al. (1993), que não encontraram indícios de influência de variáveis climáticas como precipitação e umidade relativa do ar - as mais importantes numa comparação entre o Trópico Úmido e o Semi-Árido na flutuação populacional de B. tabaci. No entanto, mesmo não havendo evidências de diferentes processos epidêmicos, é possível que o clima atue de maneira mais contundente na expressão de sintomas, como evidenciado pelo trabalho de Tatagiba et al. (2002).

\section{REFERÊNCIAS BIBLIOGRÁFICAS}

BARBOSA, C.J., MEISSNER FILHO, P.E. \& HABIBE, T.C. A meleira do mamoeiro. Bahia Agrícola 2:57. 1998.

BARBOSA, C.J., MEISSNER FILHO, P.E., HABIBE, T.C., PATROCÍNIO, E., TATAGIBA, J., NASCIMENTO, A.S. \& MATRANGOLO, W.J.R. Detecção de formas replicativas de vírus em plantas de mamoeiro inoculadas com a meleira. Summa Phytopathologica 24:60. 1998. (Resumo)

COSTA, H.S. Sweetpotato whitefly (Homoptera: Aleyrodidae): Analysis of biotypes and distribution in Hawaii. Entomological Society of America 22:16-20. 1993.

FARGETTE, D., MUNIYAPPA, V., FAUQUET, C., N'GUESSAN, P. \& THOUVENEL, J.C. Comparative epidemiology of three tropical whitefly-transmitted geminiviruses. Biochimie 75:547-554. 1993.

GIBBONS, J.D. Nonparametric methods for quantitative analysis. New York. Holt, Rinehart \& Winston. 1976.

GOTTWALD, T.R., CAMBRA, M., MORENO, P., CAMARASA, E. 
Distribuição espacial da meleira do mamoeiro em zonas de ...

\& PIQUER, J. Spatial and temporal analyses of citrus tristeza virus in eastern Spain. Phytopathology 86:45-55. 1996.

HABIBE, T.C., VIDAL, C.A., DANTAS, J.L.L. \& NASCIMENTO, A.S. Painel sintomatológico da meleira do mamoeiro e novos sintomas associados. Fitopatologia Brasileira 28:S249. 2003. (Resumo)

HIRANO, K., BUDIYANTO, E. \& WINARNI, S. Biological characteristics and forecasting outbreaks of the whitefly, Bemisia tabaci, a vector of virus diseases in soybean fields. Technical Bulletin of Food and Fertilizer Technology Center (FFTC). Taiwan. 1993. Disponível em:http://www.agnet.org/library/article/tb135.html

HUGHES, G. \& MADDEN, L.V. Aggregation and incidence of disease. Plant Pathology 41:657-660. 1992.

KITAJIMA, E.W., RODRIGUES, C.H., SILVEIRA, J.S., ALVES, F., VENTURA, J.A., ARAGÃO, F.J.L. \& OLIVEIRA, L.H.R. Association of isometric viruslike particles, restricted to laticifers, with Meleira (Sticky disease) of papaya (Carica papaya). Fitopatologia Brasileira 18:118-122. 1993.

LARANJEIRA, F.F. Dinâmica Espacial e Temporal da Clorose Variegada dos Citros. (Dissertação de Mestrado). Piracicaba. Escola Superior de Agricultura Luiz de Queiroz/Universidade de São Paulo. 1997.

MADDEN, L.V., HUGHES, G. \& ELLIS, M.A. Spatial heterogeneity of the incidence of grape downy mildew. Phytopathology 85:269-275. 1995.

MADDEN, L.V., LOUIE, R., ABT, J.J. \& KNOKE, J.K. Evaluation of tests of randomness of infected plants. Phytopathology 72:195-198. 1982.

MAFFIA, J.A., RODRIGUES, L.A. \& VENTURA, C.H. Significância epidemiológica do conhecimento do arranjo espacial de plantas doentes no campo: 1. Meleira do mamoeiro. Fitopatologia Brasileira 26:315. 1993. (Resumo)

MEISSNER FILHO, P.E., SANTOS, L.S., MOREIRA, C.V., SANTOS A.I. \& HABIBE T.C. Avaliação da transmissão da meleira pelas sementes de mamoeiro. Fitopatologia Brasileira 28:S394. 2003. (Resumo)

NAKAGAWA, J., TAKAYAMA, Y. \& SUZUKAMA, Y. Exsudação do látex pelo mamoeiro. Estudo de ocorrência em Teixeira de Freitas-
BA. In: Congresso Brasileiro de Fruticultura, 9, 1987, Campinas. Anais... São Paulo, 1987. v.1, pp.555-559.

NASCIMENTO, A.S., BARBOSA, C.J., MARQUES, O.M. \& HABIBE, T.C. Meleira e moscas-das-frutas, uma associação perigosa para a cultura do mamoeiro. Revista Bahia Agrícola 3. 1999. Disponível em: http://www.seagri.ba.gov.br/revista/rev_1199/mosca.htm

POLSTON, J.E., CHELLEMI, D.O., SCHUSTER, D.J., McGOVERN, R.J. \& STANSLY, P.A. Spatial and temporal dynamics of tomato mottle geminivirus and Bemisia tabaci (Genn.) in Florida tomato fields. Plant Disease 80:1022-1028. 1996.

RODRIGUES, C.H., ALVES, F.L. \& MARIN, S.L.D. Ocorrência e sintomas da meleira do mamoeiro (Carica papaya) no estado do Espírito Santo. Fitopatologia Brasileira 22:118. 1989a. (Resumo)

RODRIGUES, C.H., VENTURA, J.A \& MAFFIA, L.D. Distribuição e transmissão da meleira em pomares de mamão no Espírito Santo. Fitopatologia Brasileira 22:118. 1989b. (Resumo)

SANGEETA, S. Leaf curl disease of Carica papaya from India may be caused by a bipartite geminivirus. Plant Disease 82:126. 1998. (Resumo)

TATAGIBA, J.S., VENTURA, J.A., COSTA, H. \& COSTA, A.F. Evolução temporal dos sintomas da meleira do mamoeiro associada às condições climáticas. Fitopatologia Brasileira 27:214. 2002. (Resumo) VENTURA, J.A., COSTA, H \& TATAGIBA, J.S. Sintomatologia da meleira do mamoeiro e sua importância para o roguing. Fitopatologia Brasileira 26:536. 2001. (Resumo)

VIDAL, C.A. Transmissão do vírus da meleira do mamoeiro (Carica papaya L.) por insetos (Dissertação de Mestrado). Cruz das Almas. Escola de Agronomia/ Universidade Federal da Bahia. 2002.

VIEIRA, M.R. \& CORREA L.S. Ocorrência de moscas-brancas (Hemiptera:Aleyrodidae) e do predador Delphastus pusillus (LeCont) (Coleoptera:Coccinelidae)em mamoeiro (Carica papaya L.) sob cultivo em ambiente protegido. Neotropical Entomology 30:171-173. 2001.

ZAMBOLIM, E.M., BARROS, D.R., MATSUOKA, K., KUNEIDA, S., CARVALHO, M.G. \& ZERBINI, F.M. Purification and partial characterization of Papaya "Meleira" Virus. Fitopatologia Brasileira 33:442. 2000. (Resumo) 